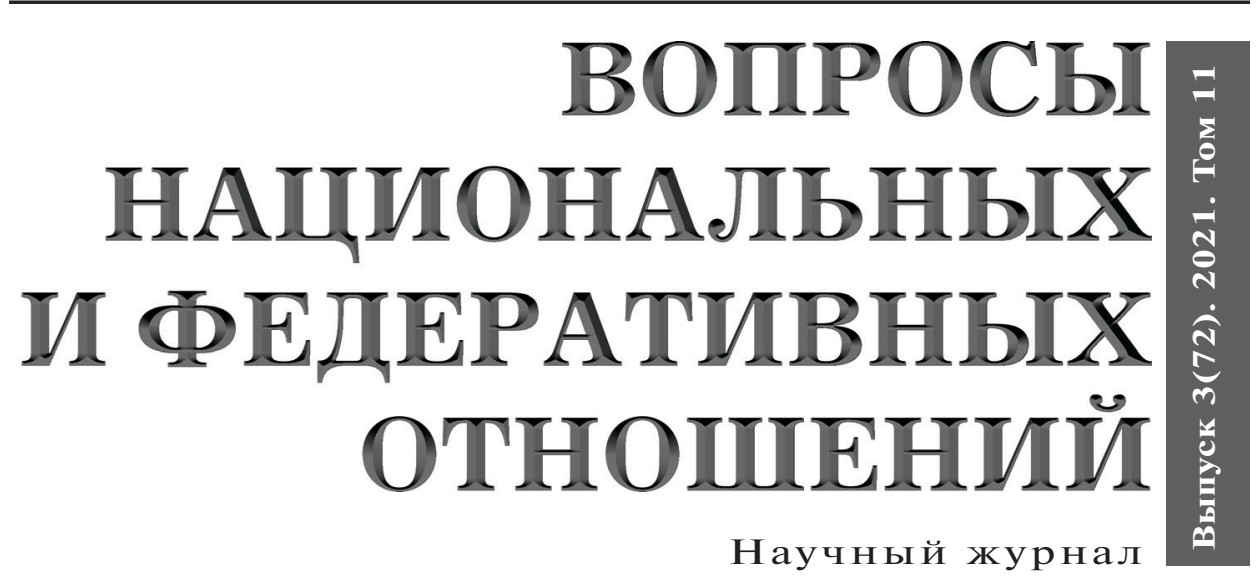

Журнал «Вопросы национальных и федеративных отношений» включен в перечень рецензируемых научных изданий ВАК, в которых должны быть опубликованы основные научные результаты на соискание ученой степени кандидата наук, на соискание ученой степени доктора наук по политическим и историческим наукам 


\section{Научный журнал}

Вячеслав Александрович МИХАЙЛОВ

Рамазан Гаджимурадович АБДУЛАТИПОВ

\section{Любовь Федоровна БОЛТЕНКОВА \\ Владимир Иванович ВАСИЛЕНКО}

Владимир Александрович ВОЛОх

Вадим Витальевич

ГАЙДУК

Леокадия Михайловна ДРОБИЖЕВА

\section{Владимир Юрьевич} ЗОРИН

Раушан Мусахановна КАНАПЬЯНОВА

\section{В. Микаэль} КАССАЕ НЫГУСИЕ

Геннадий Яковлевич КОЗЛОВ

Игорь Георгиевич КОСИКОВ

Николай Павлович МЕДВЕДЕВ

Марина Николаевна МОСЕЙКИНА

Александр Данилович НАЗАРОВ

Дарья Вячеславовна ПЕРКОВА

Александр Васильевич ПОНЕДЕЛКОВ

Дмитрий Егорович СЛИЗОВСКИЙ

Шукран Саидовна СУЛЕЙМАНОВА

Жибек Сапарбековна СЫЗДЫкОВА
Председатель Совета, д.и.н., профессор, зав. кафедрой национальных и федеративных отношений РАНХ и ГС при Президенте РФ

\section{Редакционный Совет}

д.ф.н., постоянный представитель Российской Федерации при Организации Исламского сотрудничества

д.ю.н., профессор РАНХ и ГС при Президенте РФ

д.п.н., профессор Российской академии народного хозяйства и государственной службы при Президенте РФ

д.п.н., профессор Государственного университета управления

д.п.н., профессор Башкирского государственного университета

д.и.н., руководитель Центра исследования межнациональных отношений Института Социологии ФНИСЦ РАН

д.п.н., руководитель Центра по научному взаимодействию с общественными организациями, СМИ и органами государственной власти ИЭА РАН

д.п.н., профессор кафедры международного культурного сотрудничества МГИК

д.и.н., профессор кафедры теории и истории международных отношений Российского университета дружбы народов

д.и.н., профессор Рязанского государственного университета им. С.А. Есенина

д.и.н., главный научный сотрудник Института этнологии и антропологии РАН

д.п.н., профессор Российского университета дружбы народов

д.и.н. профессор, заведующая кафедрой истории России Российского университета дружбы народов

д.и.н., профессор, зам. руководителя кафедры по научной работе Московского авиационного института к.П.н., ответственный редактор

д.п.н., профессор, заведующий кафедрой политологии и этнополитики Южно-Российского института управления - филиал РАНХ и ГС при Президенте РФ

д.и.н., профессор кафедры истории России Российского университета дружбы народов

д.п.н., профессор Российской академии народного хозяйства и государственной службы при Президенте РФ

д.и.н., профессор, заведующая кафедрой стран Центральной Азии и Кавказа Института стран Азии и Африки Московского государственного университета имени М. В. Ломоносова, заместитель главного редактора журнала

Редакционная коллегия

Главный редактор - СУЛЕЙМАНОВА Ш.С., д.п.н., профессор РАНХиГС

Члены ред. коллегии:

Волох В.А. (зам. главного редактора),

Сыздыкова Ж.С. (зам. главного редактора),

Перкова Д.В. (ответственный редактор)

Болтенкова Л.Ф., Дробижева Л.А. Слизовский Д.Е.

\author{
УЧРЕЖДЕН \\ ООО «Издательство \\ «Наука сегодня»
}

\section{ЖУРНАЛ ВКЛЮЧЕН \\ В ПЕРЕЧЕНЬ ВАК РФ}

Журнал зарегистрирован Федеральной службой по надзору в сфере массовых коммуникаций,

связи и охраны культурного наследия

Регистрационный номер

ПИ № ФС77-47487

от 25 ноября 2011 г.

Журнал издается ежемесячно

Журнал включен в базу РИНЦ

(Российский индекс научного цитирования)

Включен в каталог

Ulrich's Periodicals Directory

Пятилетний импакт-фактор журнала: 1,006

Адрес редакции:

115598 , г. Москва, ул. Загорьевская, д. 10, корп. 4, цокольный этаж, помещение I, комната 7-1, офис 4

Тел.: (910) 463-53-42

www.etnopolitolog.ru

E-mail: etnopolitolog@yandex.ru

Мнение авторов может не совпадать с мнением редакции.

При перепечатке ссылка на журнал обязательна.

Научные статьи, публикуемые в журнале подлежат обязательному рецензированию.

Ответственный редактор Перкова Д.В.

Компьютерная верстка Анциферова А.С.

Подписано в печать 25.03.2021.

Формат 60×84/8. Объем 24,3. Печать офсетная. Тираж - 1000 экз. (1-й завод - 500 экз.) Заказ № 0000

Отпечатано в типографии ООО «Белый ветер»

115054, г. Москва, ул. Щипок, 28

Тел.: (495) 651-84-56 
ISSN 2226-8596 (print)

12 выпусков в год и

2 выпуска в год переводной (англ.) версии

Языки: русский, английский

http://etnopolitolog

Входит в перечень рецензируемых научных изданий ВАК РФ

Включен в каталог периодических изданий Ульрих (Ulrich's Periodicals Directory: http://www.ulrichsweb.com) Материалы журнала размещаются на платформе РИНЦ Российской научной электронной библиотеки, Electronic Journals

Library Cyberleninka

Подписной индекс издания в каталоге агентства Роспечать 70114

\section{Цели и тематика}

Журнал ВОПРОСЫ НАЦИОНАЛЬНЫХ И ФЕДЕРАТИВНЫХ ОТНОШЕНИЙ - периодическое международное рецензируемое на ᄀучное издание в области политических исследований. Журнал является международным как по составу редакционного совета и редколлегии, так и по авторам и тематике публикаций.

Научный журнал издается с 2011 года в издательстве «Наука сегодня». С 2018 года издается переводная (англ.) версия журнала. С момента своего создания, журнал ориентировался на высокие научные и этические стандарта и сегодня является одним из ведущих политологических журналов России.

Цель журнала - способствовать научному обмену и сотрудничеству между российскими и зарубежными политологами

Журнал предназначен для публикации результатов фундаментальных и прикладных научных исследований. Тематическая направленность журнала отражается в следующих постоянных рубриках: «Отечественная история, этнология и этнография», «История международных отношений и мировой политики», «История и философия политики», «Политические институты, процессы и технологии», «Политическая культура, этнополитика и идеологии», «Политические проблемы международных отношений и глобализации».

Формат публикаций: научные статьи, обзорные научные материалы, материалы круглых столов, научные рецензии, научные сообщения, посвященные исследовательским проблемам в сфере политики и политологии.

В своей деятельности редакционный совет и редколлегия журнала руководствуется принципами, определяемыми ВАК России для научных журналов, в том числе: наличие института рецензирования для экспертной оценки качества научных статей; информационная открытость издания; наличие и соблюдение правил и этических стандартов представления рукописей авторами.

Целевой аудиторией журнала являются российские и зарубежные специалисты-политологи, а также аспиранты и магистры, обучающиеся по направлениям политология, государственное и муниципальное управление и международные отношения.

Журнал строго придерживается международных стандартов публикационной этики, обозначенных в документе СОРЕ (Committee on Publication Ethics) http://publicationethics.org

Полные сведения о журнале и его редакционной политике, требования о подготовке и публикации статей, архив (выпуски с 2011 года) и дополнительная информация размещена на сайте: http://etnopolitolog.ru

Электронный адрес: etnopolitolog@yandex.ru

ISSN 2226-8596 (print)

12 issues a year plus 2 issues a year of the translated (eng.) version Languages: Russian and English http://etnopolitolog

Included in the list of peer-reviewed scientific publications of the Higher Attestation Commission of the Russian Federation Included in the Ulrich's Periodicals Directory Materials of the journal are placed on the RSCI platform of the Russian scientific electronic library - Electronic Journals Library Cyberleninka Subscription index of the journal in the Rospechat Agency catalogue is: 70114

\section{Objectives and themes}

Academic journal "Issues of National and Federative Relations" is an international peer-reviewed scientific periodical in the field of political studies. The journal has an international character because of the composition of its Editorial Board, its editors, its contributing authors and topics of its publications.

The scientific journal is published since 2011 at the "Publishing House "Science Today". Translated (eng.) version of the journal is published since 2018. Since its inception, the journal was guided by high scientific and ethical standards and today it is one of the leading political science journals in Russia.

The purpose of the journal is to promote scientific exchange and cooperation between Russian and foreign political scientists.

The journal is intended for the publication of the results of fundamental and applied scientific research. Thematic focus of the journal is reflected in the following permanent headings: "Domestic history, ethnology and ethnography", "History of international relations and world politics", "History and philosophy of politics", "Political institutions, processes and technologies", "Political culture, ethnopolitics and ideologies", "Political problems of international relations and globalization."

Format of publications: scientific articles, reviews, scientific materials, materials of round tables, scientific reviews, scientific reports devoted to research problems in the field of politics and political science.

The Editorial Board and the editors of the journal in their activities are guided by the principles defined by VAK of Russia for scientific journals, including: presence of the institute of peer review for the expert quality assessment of scientific articles; information openness of the publications; availability and compliance with the rules and ethical standards for the submission of manuscripts by the authors.

The target audience of the journal is Russian and foreign specialists-political scientists, as well as graduate students and masters in the fields of political science, state and municipal management and international relations.

The journal strictly adheres to the international publishing standards and publication ethics identified in the COPE (COmmittee on Publication Ethics) document. http://publicationethics.org.

Full details of the journal and its editorial policy, requirements to the preparation and publication of articles, archive (issues since 2011) and additional information are available on the website: http://etnopolitolog.ru

E-mail address: etnopolitolog@yandex.ru 
ОТЕЧЕСТВЕННАЯ ИСТОРИЯ, ЭТНОЛОГИЯ И ЭТНОГРАФИЯ

Емельянова A.A. Сезонность браков мещан

в Москве в первой половине XIX в.

(на материале Никитского сорока)

Занозин Н.В. Формирование и развитие

номенклатуры Горьковского обкома партии

в послевоенный период (1945-1953 гг.)

Кузнецов В.Н. Значение предпринимательства

в развитии внутренней торговли на Северо-Западе России

во второй половине XIX века..

Емельянова E.A., Погорелов С.C. Политика советской власти

в отношении русской православной церкви на Кубани

в 1920-1940 годы ХХ века

Бровченко И.Ю. Практический аспект

православно-католического диалога

в политике современности

Ванькина $\boldsymbol{E} . \boldsymbol{A}$. К вопросу о выборах мировых судей

в провинциальных уездах Российской империи

Eвстратов М.B. Подготовка младшего

командного состава РККА в период реорганизации

1939-июнь 1941 гг. некоторые аспекты

Ильясов Л.М. Древние и средневековые

культовые сооружения Чечни

Крупская О.А. Польский вопрос

и особенности русско-польских отношений в XIX веке

Tитерина В.К. Динамика внешнеполитического

курса России в конце XVII начале XVIII вв.

Чичерин P.Г. Образ США в российском политическом

руководстве времен правления Б.Н. Ельцина.

Пищук М.Д. «Год первый»: Госкомнац России

и его деятельность по защите русскоязычного населения

на постсоветском пространстве в 1992 году

Шиматюк О.А. Формирование энергетического диалога между Европейским Союзом и Российской Федерацией в 1990-2000-х гг.

ТЕОРИЯ, ФИЛОСОФИЯ И ИСТОРИЯ ПОЛИТИКИ

Болтенкова Л.Ф. Библия как источник права (часть шестая)

\section{ПОЛИТИЧЕСКАЯ РЕГИОНАЛИСТИКА И ЭТНОПОЛИТИКА}

$\boldsymbol{H и к л а у с ~} \boldsymbol{A}$. $\boldsymbol{A}$. Роль культурного самоопределения территориальных меньшинств в процессе формирования внутрирегионального пространства государств: отечественный и европейский опыт 
Цветкова О.В. Нациестроительство и языковая политика в современной России (по материалам этносоциологического исследования).

\section{ПОЛИТИЧЕСКИЕ ИНСТИТУТЫ, ПРОЦЕССЫ И ТЕХНОЛОГИИ}

Рубан Л.С. Влияние внешних факторов на развитие

Российской Федерации в условиях новой социальной реальности

Попов С.И., Ериов Н.А., Омерович А.Р. Протестный потенциал как инструмент предвыборной кампании (Часть II:

Выборы в Государственную Думу 2021 года. Прогнозы)

Алсалиби Риваа Мухаммад Салем. Этнические группы на страницах социальных сетей в России

Шихер Н.Д. Институциональные формы государственно-конфессионального взаимодействия в современной России

Линдо A.B. Политика трудовой миграции в регионах: сетевая теория в контексте принятия политических решений 884

ТЕОРИЯ И ИСТОРИЯ МЕЖДУНАРОДНЫХ ОТНОШЕНИЙ, ВНЕШНЕЙ И МИРОВОЙ ПОЛИТИКИ

Моисеев А.В., Шангараев Р.Н. Межгосударственное сотрудничество по снижению рисков глобальных ядерных угроз: концепции и практика

Альжсаруан Мохд Хиер Джсаруан. Иранские международные альянсы в контексте сирийского кризиса: российско-иранские отношения 900

Шолкова М.А. Деятельность Японии в сфере миротворчества. 905 Семенова О.В. Моделирование во внешнеполитической деятельности 910 Абахра Мушир Ибрагим Хасан, Шехада Мо Мин Т.Ф.

Распространение демократии как метод внешней политики США на Ближнем Востоке 916

Новикова К.А. Эволюция фактора социальных медиа в протестах на территории Испании

Бирюков П.Э. Реализация национальных интересов России в международных транспортных коридорах. 933

Капитонов $\boldsymbol{A}$. $\boldsymbol{A}$. Влияние итогов президентских выборов 2020 года в США на реализацию целей в области устойчивого развития в национальном и глобальном измерениях 943

Полтавцева О.Н. Новые медиа и политическая коммуникация в Италии. Сильвио Берлускони, Беппе Грилло, Маттео Сальвини 961 
Овчинников Д.С., Шпак М.С., Нечай Е.Е. Северный поток-2:

политические противоречия коммерческого проекта. 966

РАЗМЫШЛЕНИЯ НАД ПРОЧИТАННЫМ

Медведев Н.П. К вопросу о сущности понятия

«нациестроительство». Размышления над прочитанным

КОНФЕРЕНЦИИ

Караев T.M. Конференция, посвященная наследию осетинского поэта и мыслителя К.Л. Хетагурова «Весь мир - мой храм» 981

НАШИ АВТОРЫ 985

ТРЕБОВАНИЯ К ОФОРМЛЕНИЮ РУКОПИСЕЙ 992 
DOI 10.35775/PSI.2021.72.3.033

УДК 32.327

T.M. КАРАEB

доктор философских наук,

профессор философского факультета

МГУ имени М.В. Ломоносова,

Россия, г. Москва

\title{
КОНФЕРЕНЦИЯ, ПОСВЯЩЕННАЯ НАСЛЕДИЮ ОСЕТИНСКОГО ПОЭТА И МЫСЛИТЕЛЯ К.Л. ХЕТАГУРОВА «ВЕСЬ МИР - МОЙ ХРАМ»
}

\author{
T.M. KARAEV \\ Doctor of Philosophy, Professor, \\ Faculty of Philosophy, Lomonosov Moscow \\ State University, Moscow, Russia
}

\section{CONFERENCE ON THE HERITAGE OF OSSETIAN POET AND THINKER K.L. KHETAGUROV "THE WHOLE WORLD IS MY TEMPLE"}

25 февраля 2021 г. в Московском государственном университете имени М.В. Ломоносова, на базе Института стран Азии и Африки и философского факультета, кафедрами стран центральной Азии и Кавказа и истории русской философии проведена международная конференция, посвященная наследию осетинского просветителя, мыслителя и поэта К.Л. Хетагурова. Тема конференции: «Весь мир - мой храм» наследие К.Л. Хетагурова, осетинского поэта и мыслителя.

Конференция организована в рамках проекта ИСАА «Интеллектуальное наследие народов мира, интеллектуальное наследие народов России».

В работе конференции приняли участие исследователи и эксперты из России, Казахстана, Узбекистана, Киргизии, Украины, Таджикистана, Пакистана, Германии. С докладами на конференции выступили исследователи из МГУ имени Ломоносова, Северо-Осетинского государственного университета им. К.Л. Хетагурова, Северо-Осетинского центра гуманитарных и социальных исследований им. В. Абаева, других учебных заведений и организаций.

С докладом «История философской и общественной мысли народов СССР как объект для научных исследований» выступил заслуженный про- 
фессор МГУ имени М.В. Ломоносова, заведующий кафедрой истории русской философии философского факультета МГУ Маслин М.А. В своем выступлении он отметил важность сохранения в настоящее время ориенталистских исследований, которые успешно проводились в Советском Союзе. Кафедра истории философии народов СССР выпускала специалистов-историков философии для всех союзных республик, многие из которых в настоящее время продолжают работать. В выступлении Маслина М.А. отмечена актуальность межфакультетского исследовательского сотрудничества, примером чему является совместная работа кафедры стран Центральной Азии и Кавказа ИСАА МГУ и кафедры истории русской философии философского факультета МГУ. М.А. Маслин также отметил, что одним из приоритетных научно-исследовательских направлений Московского университета в гуманитарной сфере является тема истории культуры народов России.

В докладе заведующего кафедрой истории стран Центральной Азии и Кавказа профессора Сыздыковой Ж.С. обращено внимание на уникальное наследие К. Хетагурова, добившегося, несмотря на огромные трудности детства, обучения в разных учебных заведениях, включая СанктПетербургскую академию художеств, значительных успехов. Это и поэзия, и эстетика, и публицистика, в которых отражена жизнь не только Осетии, но и всего Северного Кавказа. Докладчик особо выделил значимость изучения творческого наследия Коста Хетагурова для современной молодежи.

В докладе заслуженного профессора МГУ имени М.В. Ломоносова, профессора философского факультета МГУ, заведующего кафедрой гуманитарных дисциплин СУНЦ МГУ Караева Т.М. отмечено, что все наследие К. Хетагурова насыщено идеями социальной философии. Хетагуров выступил как гражданский омбудсмен, он поднял вечный вопрос социальных идеалов всех народов - это социальная справедливость. Тема, входящая как базисное требование в Конституции большинства стран мира, включая Россию. Хетагуров поднимает вопросы бедности, унижающие человеческое достоинство, выступает как критик детского труда и как критик эксплуатирующего труда. В докладе Караева Т.М. отмечено, что в социальной философии К. Хетагурова актуализирована тема консолидации гражданского общества, могущего изменить положение с социальной необустроенностью. Наследие Хетагурова актуально и тем, что многие вопросы, которые он поднимал, транслируются в национальных программах, реализуемых в современной России.

Профессор кафедры философии Ярославского высшего военного училища противовоздушной обороны Дадианова Т.В. в докладе «К. Хетагуров и М. Кипиани. Грузинская школа во Владикавказе как проявление толерантности осетин» подчеркнула значимость просветительской деятельности К. Хетагурова. В частности, она исследовала сотрудничество К. Хетагурова с грузинским просветителем М. Кипиани. Оба мыслителя приложили много 
усилий для открытия грузинской школы во Владикавказе, функционирующей до настоящего времени. По мнению докладчика, данный биографический факт из жизни К. Хетагурова является проявлением толерантности осетин. По мнению Дадиановой Т.В., наследие К. Хетагурова возрастает в своем величии, так как он боролся за судьбу осетинского народа.

В докладе доцента Северо-Осетинского института гуманитарных и социальных исследований им В. Абаева Мамиевой И.В. «Национальная картина мира в поэзии К. Хетагурова в лексикографическом обрамлении» подчеркнуто, что не только все творческое наследие К. Хетагурова, а уже созданная им «Осетинская лира», сборника стихов на осетинском языке, является подвижническим актом и творческим подвигом на инициирование личностного и национального самосознания осетин. По мнению автора доклада, К. Хетагуров - личность, объединяющая разрозненность на хаотические детали мир патриархальной Осетии, личность - структурирующая национальный «космос» осетинской души. Неслучайно Хетагуров называет весь мир своим храмом, Вселенную - отечеством своим.

В докладе Бязровой Л.В. «Романтизм в изобразительном творчестве К. Хетагурова» обращено внимание на то, что Хетагуров был вовлечен в сферу влияния романтизма, мощного движения первой половины 19 века в европейском искусстве. В докладе подчеркнуто, что осетинское изобразительное искусство, благодаря К. Хетагурову, перешагнуло упущенные ступени и рубежи, стремясь в 20 век. По мнению автора доклада, К. Хетагуров в своих картинах, особенно после возвращения из Петербурга, ставит проблемы, связанные с местом человека в природе. В работах К. Хетагурова проявлена удивительная особенность - умение обобщать. Портретная живопись К. Хетагурова - это показ не столько принадлежности к сословию, сколько индивидуальность и личные качества человека. Изобразительное искусство К. Хетагурова определило открытость национальной культуры тенденциям мирового художественного процесса.

Доклад Дзапаровой Е.Б., канд. фил. наук (Северо-Осетинский институт гуманитарных и социальных исследований им В. Абаева) «Первый русскоязычный перевод стихотворения К.Л. Хетагурова «Мать сирот»: лексико-семантический анализ» посвящен разбору уникального поэтического произведения «Мать сирот». В докладе подробно разобрана проблема с т.з. современного лексико-семантического анализа, но вместе с тем, в докладе подчеркнуто, что при переводе нюансы оригинала не утеряны, сохранены и в полном объеме передают содержание. Автор подчеркивает, что Л. Кипиани явился первой русскоязычной интерпретацией произведений Хетагурова с осетинского языка. Основная концепция перевода - это сохранение идеи и эстетики текста. Данная концепция на примере перевода произведений К. Хетагурова удачно реализована. 
Доклад Буряченко Т.И. «Творчество К. Хетагурова как объект изучения и как предмет преподавания на занятиях по русскому языку как неродному» из Кыргызского национального университета им. Ж. Баласагына посвящен использованию поэтических произведений Хетагурова в процессе изучения русского языка. Используются фразеологизмы поэзии К. Хетагурова, по мнению автора доклада, идейная глубина произведений К. Хетагурова способствует воспитанию патриотизма.

Доклад Бакановой М.В. из Пакистана под названием «Послания молодежи К. Хетагурова и А.М. Икбала - поэтов современников» посвящен культурологическому, текстологическому и идейному анализу-сопоставлению двух прославленных поэтов разных национальностей, живших в разных концах света в одно и то же время. Автор доклада замечает, что элементов универсализма в наследии поэтов на порядок выше, чем единичных. Оба мыслителя обращаются к молодежи, их волнует будущее своих народов, оба мыслителя размышляют над тем как достичь справедливого социального идеала. 